DOI: 10.12731/2658-6649-2020-12-5-22-31

УДК 574.34:582.572.2

\title{
ИЗМЕНЧИВОСТЬ МОРФОЛОГИЧЕСКОЙ СТРУКТУРЫ РАСТЕНИЙ В ЦЕНОПОПУЛЯЦИЯХ TULIPA BIEBERSTEINIANA SCHULT. ET SCHULT. (LILIACEAE) В УСЛОВИЯХ КАЛМЫКИИ
}

\author{
Анжаев Н.О., Борлыков С.Х., \\ Овадыкова Ж.В., Лиджиева Н.Ц.
}

В статье приведены данные по изучению изменчивости морфологической структуры растений в популяциях Tulipa biebersteiniana Schult. et Schult. (Liliaceae), произраставщих в пределах двух крупных геоморфологических структур Республики Калмыкия - Прикаспийской низменности и Долине Маныча. В Долине Маныча видовая популячия № 1 произрастала в составе разнотравно-злакового (Poасеае-Mixteherbosa) сообщества и иенопопуляцию № 2 в составе разнотравно-типчаково-полынкового (Artemisia austriaca-Festuca valesiaca-Mixteherbosa) сообщества, произрастающих на лугово-каштановых почвах. В Прикаспийской низменности видовая популячия № 3 входила в состав эфемерово-луковичномятликового (Poa bulbosa-Epheтеrosa) сообщества; иченопопулящию № 4 в состав эфемерово-луковичномятликово-лерхопольнное (Artemisia lercheana-Poa bulbosa-Epheтегоsa) сообщества, которые произрастают бурых пустынно-степных солонцеватых почвах.

Растения из иенопопулящий T. biebersteiniana, произрастаюших в Долине Маныча, имели большие значения признаков, чем ценопопулячии с Прикаспийской низменности. В ценопопуляциях T. biebersteiniana наибольшее значение всех признаков растений отмечали в 2017 году, наименьшее - 6 2016 году, что свидетельствует о более благоприятных для роста и развития растений погодных условиях в этот год.

В иенопопуляииях T. biebersteiniana девять морфологических признаков, характеризующих вегетативную и генеративную сферу растений варьрировали в 2016 на высоком и среднем уровнях изменчивости, в 2017 году - преимущественно на высоком уровне изменчивости.

Ключевые слова: тюльпан Биберштейна; ценопопуляция; изменчивость морфологических признаков; охрана растений. 


\title{
VARIABILITY OF MORPHOLOGICAL STRUCTURE OF PLANTS IN TULIPA BIEBERSTEINIANA SCHULT. ET SCHULT. (LILIACEAE) COENOPOPULATIONS IN KALMYKIA
}

\author{
Anzaev N.O., Borlikov S.H., \\ Ovadykova Zh.V., Lidzhieva N.Ts.
}

The article presents data on the study of the variability of the morphological structure of plants in populations of Tulipa biebersteiniana Schult. et Schult. (Liliaceae), growing within two large geomorphological structures of the Republic of Kalmykia - the Caspian lowland and the Manych Valley. In the Manych Valley, the species population № 1 grew as part of a mixed-grass (Poaceta-Mixteherbosa) community and coenopopulation № 2-as part of a mixed-grass-type-wormwood (Artemisia austriaca-Festuca valesiaca-Mixteherbosa) community on meadow-chestnut soils. In the Caspian lowland, the species population № 3 was part of the ephemeral-bulbous dwarf (Poa bulbosa-Ephemerosa) communities and coenopopulation № 4 in the ephemeral-bulbous-dwarf-lerchopolyn (Artemisia lercheana-Poa bulbosa-Ephemerosa) communities on brown desert-steppe saline soils.

Plants from the coenopopulations of T. biebersteiniana growing in the Manych Valley had higher values of traits than coenopopulations from the Caspian lowland. In the coenopopulations of T. biebersteiniana, the highest value of all plant traits was noted in 2017, and the lowest value was noted in 2016, which indicates that the weather conditions of this year are more favorable for plant growth and development.

In the coenopopulations of T. biebersteiniana, nine morphological features that characterize the vegetative and generative spheres of plants varied in 2016 at high and medium levels of variability, in 2017 - mainly at a high level of variability.

Keywords: Tulipa biebersteiniana; cenopopulation; variability of morphological features; plant protection

\section{Введение}

Углубление знаний по популяционной экологии и биологии вида будет способствовать формированию представлений о механизмах, которые обеспечивают устойчивость ценопопуляций в природных растительных со- 
обществах [1]. Особенно актуальной эта проблема становится для видов, отнесенных к числу редких и исчезающих, поскольку поможет объективно оценить состояние популяций таких видов, выработать рекомендации по их охране. Во флоре Калмыкии представители семейства Лилейные относятся к числу особенно уязвимых из-за возрастающего антропогенного воздействия. Проведен ряд популяционных исследований некоторых видов рода Tulipa [2-4 и др.], однако для аридных условий работы в данном направлении начаты сравнительно недавно [5-7].

Цель исследования стало выявление внутривидовой изменчивости морфологической структуры растений ценопопуляций Tulipa biebersteiniana Schult. et Schult. (Liliaceae), произрастающих в пределах двух крупных геоморфологических структур Республики Калмыкия - Прикаспийской низменности и Долине Маныча.

\section{Материалы и методы исследования}

Объект нашего исследования - луковичный эфемероид Tulipa biebersteiniana Schult. et Schult. (тюльпан Биберштейна) - один из трех видов тюльпанов, произрастающих в Республике Калмыкия. Вид отнесён к числу охраняемых во многих регионах России [8, 9, 10 и др.]. В Красной книге Калмыкии [11] вид имеет категорию редкости III - «редкий вид».

Популяции Tulipa biebersteiniana исследовали в пределах двух крупных геоморфологических структур Калмыкии - Прикаспийской низменности и Долине Маныча. В Долине Маныча видовая популяция № 1 произрастала в составе разнотравно-злакового (Рoaceae-Mixteherbosa) coобщества и ценопопуляцию № 2 в составе разнотравно-типчаково-полынкового (Artemisia austriaca-Festuca valesiaca-Mixteherbosa) сообщества, произрастающих на лугово-каштановых почвах. В Прикаспийской низменности видовая популяция № 3 входила в состав эфемерово-луковичномятликового (Poa bulbosa-Ephemerosa) сообщества; ценопопуляцию № 4 в состав эфемерово-луковичномятликово-лерхополынное (Artemisia lercheana-Poa bulbosa-Ephemerosa) сообщества, которые произрастают бурых пустынно-степных солонцеватых почвах.

Принадлежность исследуемого вида к моцентрической биоморфе позволила использовать в качестве единицы учета в ценопопуляции вида отдельное растение - особь семенного воспроизведения [12]. В пределах популяции брали случайную выборку из 30 и более растений в средне генеративном возрастном состоянии для учета морфологических признаков генеративных и вегетативных органов. Изменчивость признака оценивали 
с помощью коэффициента вариации (Cv, \%). При этом уровень варьирования признака определяли по Г.И. Зайцеву [13]. Для статистической обработки данных использовали программы MS EXCEL, 2007 и STATISTIKA 7.0.

\section{Результаты исследования}

При характеристике морфологической структуры особей T. biebersteiniana изучали изменчивость 9 морфологических признаков. Высота растений в первый год исследования варьировала на среднем уровне изменчивости $\left(\mathrm{C}_{\mathrm{v}}=17,3-19,5 \%\right)$, во второй год в ценопопуляциях с Долины Маныча варьировали на высоком уровне $\left(\mathrm{C}_{\mathrm{v}}=18,7\right.$ и $\left.19,2 \%\right)$.

Анализ высоты растений в ценопопуляциях T. biebersteiniana выявил, что в период проведения исследований в ценопопуляции № 1 она больше, чем в трех других исследованных ценопопуляциях. Так в 2016 году высота растений в данной ценопопуляции была больше по сравнению с ценопопуляцией №2 на 24,6 мм (t diff $=3,24$, при $\mathrm{P}<0,05)$, с ценопопуляцией № 3 - на 30,5 мм (t diff $=3,66$, при $\mathrm{P}<0,01)$, с ), с ценопопуляцией № 4 - на 40,0 мм (t diff $=2,99$, при $\mathrm{P}<0,01)$ (табл. 1$)$.

Таблица 1.

Изменчивость высоты растения (мм) в ценопопуляциях Tulipa biebersteiniana

\begin{tabular}{|c|c|c|c|c|c|c|c|c|}
\hline Ценопопуляция & Год & $\overline{\mathrm{x}}$ & $\mathrm{S}_{\overline{\mathrm{x}}}$ & $\mathrm{S}_{\mathrm{x}}$ & $\mathrm{C}_{\mathrm{v}}$ & $\mathrm{S}_{\mathrm{cv}}$ & $\min$ & $\max$ \\
\hline \multirow{2}{*}{$№ 1$} & 2016 & 152,3 & 5,70 & 35,10 & 19,5 & 2,07 & 114 & 252 \\
\cline { 2 - 9 } & 2017 & 244,5 & 12,14 & 51,42 & 25,1 & 4,95 & 148 & 302 \\
\hline \multirow{2}{*}{$№ 2$} & 2016 & 140,0 & 5,58 & 27,33 & 18,1 & 2,81 & 90 & 198 \\
\cline { 2 - 9 } & 2017 & 208,9 & 10,45 & 38,61 & 21,0 & 3,04 & 110 & 230 \\
\hline \multirow{2}{*}{$№ 3$} & 2016 & 101,7 & 4,13 & 27,01 & 17,9 & 1,95 & 83 & 173 \\
\cline { 2 - 9 } & 2017 & 125,9 & 5,91 & 29,22 & 19,2 & 2,19 & 67 & 182 \\
\hline \multirow{2}{*}{ №4 } & 2016 & 134,5 & 3,41 & 28,50 & 17,3 & 1,71 & 106 & 198 \\
\cline { 2 - 9 } & 2017 & 176,9 & 7,77 & 30,55 & 18,7 & 1,98 & 114 & 232 \\
\hline
\end{tabular}

Из двух лет исследования в 2017 году растения T. biebersteiniana были значительно больше, чем в 2016 году: в ценопопуляции № 1 на 92,2 мм ( $\mathrm{t}$ diff $=6,88$, при $\mathrm{P}<0,001)$, в ценопопуляции № 2 на 68,9 мм ( $\mathrm{t}_{\text {diff }}=6,28$, при $\mathrm{P}<0,001)$, в ценопопуляции № 3 на 24,5 мм ( $\mathrm{t}_{\text {diff }}=3,40$, при $\left.\mathrm{P}<0,01\right)$, в ценопопуляции № 4 на 42,4 мм ( $\mathrm{t}_{\text {diff }}=5,00$, при $\left.\mathrm{P}<0,001\right)$.

Кроме высоты растений у T. biebersteiniana изучали изменчивость еще 8 морфологических признаков, которые составили в среднем: длина междоузлия в 2016 году 16,5 мм, в 2017 году 21,0 мм, длина цветочной стрелки в 2016 году 105,2 мм, в 2017 году 118,8 мм, длина лепестка в 2016 году 
22,85 мм, в 2017 году 30,7 мм, ширина лепестка в 2016 году 6,85 мм, в 2017 году 12,6 мм, длина нижнего листа в 2016 году 117,2 мм, в 2017 году 143,2 мм, ширина нижнего листа в 2016 году 5,75 мм, в 2017 году 6,6 мм, длина верхнего листа в 2016 году 92,55 мм, в 2017 году 110,7 мм, ширина верхнего листа в 2016 году 4,5 мм, в 2017 году 5,0 мм (рис. 1).

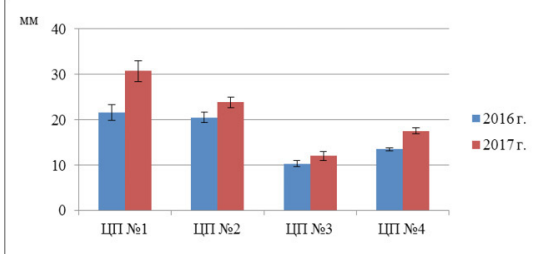

1. Длина междоузлия

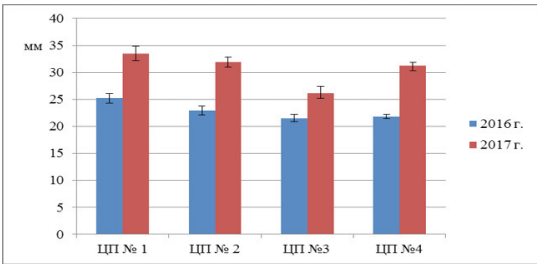

3. Длина листочка околоцветника

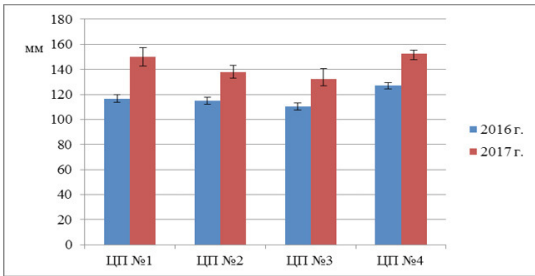

5. Длина нижнего листа

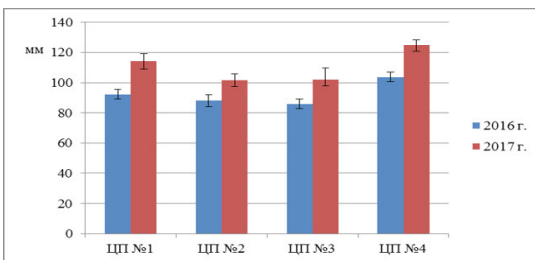

7. Длина верхнего листа

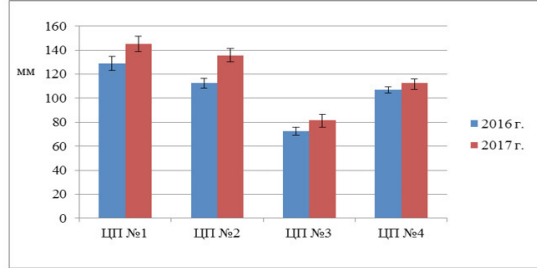

2. Длина цветочной стрелки

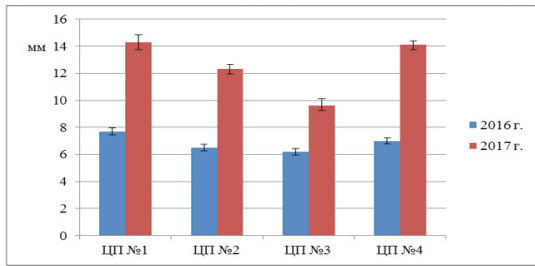

4. Ширина листочка околоцветника

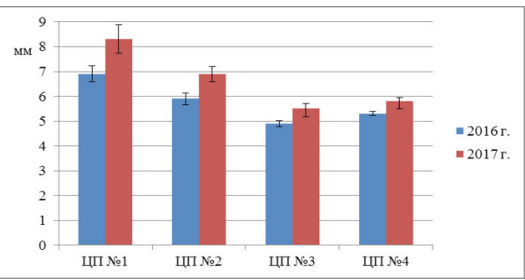

6. Ширина нижнего листа

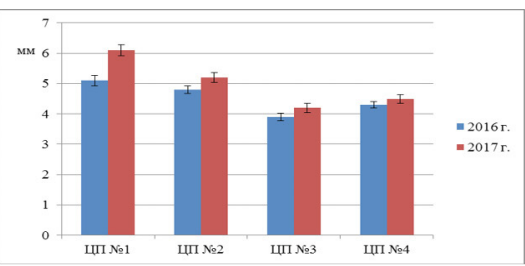

8. Ширина верхнего листа

Рис. 1. Изменчивость морфологических признаков в ценопопуляциях T. biebersteiniana 
Все исследованные признаки растений T. biebersteiniana обнаружили сходную с высотой растения изменчивость зависимости от геоморфологической структуры и года исследования. При этом в Долине Маныча исследованные признаки T. biebersteiniana в 2016 году обнаружили средний и высокий уровни изменчивсоти, а в 2017 году - высокий уровень изменчивости, за исключением длины и ширины листочков околоцветника. В Прикаспийской низменности в оба года исследования отмечали средний и высокий уровни изменчивости.

\section{Обсуждение}

В природных видовых популяциях T. biebersteiniana в Долине Маныча по всем исследованным морфологическим признакам растения имели большие значения признаков, чем в Прикаспийской низменности, Подобная изменчивость биоморфологических признаков обусловлена спецификой эколого-фитоценотических условий, которые складываются в растительных сообществах в данных двух крупных геоморфологических структурах Калмыкии, в которых произрастают исследованные ценопопуляции.

Выявленное во всех исследованных ценопопуляциях T. biebersteiniana преобладанием показателей растений в 2017 году по сравнению с 2016 годом в значительной степени обусловлено погодными условиями этого года, особенно в период активной вегетации растений. Ранневесенние месяцы 2017 года в районе исследования характеризовались большими суммарными объемами осадков апреля и более низкими температурами марта и апреля, когда происходила активная вегетация растений.

\section{Заключение}

Таким образом, в ценопопуляциях T. biebersteiniana выявлена специфика изменчивости биоморфологических признаков в разные годы и в зависимости от эколого-фитоценотических условий произрастания в разных геоморфологических структурах в пределах Республики Калмыкия.

\section{Список литературы}

1. Работнов Т.А. Вопросы изучения состава популяций для целей фитоценологии // Проблемы ботаники. Л., 1950. Т.1. С. 465-483.

2. Тимошенкова В.В. Зависимость жизненного состояния ценопопуляций Tulipa orhiophylla от степени антропогенной трансформации растительности // Промышленная ботаника. 2007. №7. С. 19-26. 
3. Кашин A.C. с соавт. Структура ценопопуляций Tulipa gesneriana L. (Liliaceae) в Саратовской области // Биоразнообразие аридных экосистем. 2014. C. 86-105.

4. Мухаметшина Л.В. Изменчивость морфологических признаков некоторых видов рода Tulipa L. на Южном Урале / Л.В. Мухаметшина, Э.3. Муллабаева, М.М. Ишмуратова // Известия Самарского научного центра Российской академии наук. 2014. Т. 16. №. 5-5. С. 1650-1653.

5. Лыу Т.Н. Изменчивость признаков растений Tulipa gesneriana в ценопопуляции, полиморфной по окраске цветков / Т.Н. Лыу, Р.В.Бадаев, Д.А. Обгенова, Н.Ц. Лиджиева // Вестн. Калмыцкого ун-та. 2013. №1 (17). С. 39-43.

6. Очирова А.С. Фитоценотическая приуроченность ценопопуляции Tulipa biflora в Калмыкии / А.С. Очирова, О.В. Кондышев, Ж.В. Овадыкова, Н.Ц. Лиджиева // В мире научных открытий. Красноярск, 2015. № 2 (62). С. 53-66.

7. Очирова А.С. Семенная продуктивность растений в ценопопуляциях Tulipa biflora в условиях Республики Калмыкия / А.С. Очирова, А.М. Головкова, Ж.В. Овадыкова, Н.Ц. Лиджиева // В мире научных открытий. Красноярск, 2017. Т.9. №4 (2). С. 137-149.

8. Красная книга Волгоградской области. (Растения и грибы) / Комитет охраны природы Администрации Волгоградской области. Волгоград: изд-во Волгоград, 2006. Т. 2. 236 с.

9. Красная книга Краснодарского края. (Растения и грибы) / Отв. ред. С.А. Литвинская. 2-е изд. Краснодар: ООО «Дизайн Бюро № 1», 2007. 640 с.

10. Красная книга Ростовской области: в 2 т. Растения и грибы / науч. ред. В.В. Федяева. Ростов-на-Дону: Минприроды Ростовской области, 2014. Т. 2.344 с.

11. Красная книга Республики Калмыкия: в 2 т. Т.2. Редкие и находящиеся под угрозой исчезновения растения и грибы / отв. ред. Н.М. Бакташева. Элиста: ЗАОр «НПП «Джангар», 2014. 199 с.

12. Ценопопуляции растений (основные понятия и структура) / Отв. ред. А.А. Уранов, Т.И. Серебрякова. М.: Наука, 1976. 217 с.

13. Зайцев Г.Н. Математический анализ биологических данных. М.: Наука, 1991. $180 \mathrm{c}$.

\section{References}

1. Rabotnov T.A. Zhiznennyy tsikl mnogoletnikh travyanistykh rasteniy v lugovykh tsenozakh [The life cycle of perennial herbaceous plants in meadow cenoses]. Geobotanika [Geobotany]. M. L.: Proceedings of the Bot. Institute app. V.L. Komarova AS of the USSR. 1950, ser. III. issue. 6, pp. 7-197. 
2. Timoshenkova V.V. Zavisimost' zhiznennogo sostoyaniya tsenopopulyatsiy Tulipa orhiophylla ot stepeni antropogennoy transformatsii rastitel'nosti [Dependence of the vital status of coenopopulation Tulipa orhiophylla on the degree of anthropogenic transformation of vegetation]. Promyshlennaya botanika [Industrial Botany], 2007, № 7, pp. 19-26.

3. Kashin A.S. i dr. Struktura tsenopopulyatsiy Tulipa gesneriana L. (Liliaceae) v Saratovskoy oblasti [Structure of coenopopulations of Tulipa gesneriana L. (Liliaceae) in the Saratov Region]. Bioraznoobraziye aridnykh ekosistem [Biodiversity of arid ecosystems], 2014, pp. 86-105.

4. Mukhametshina L.V., Mullabayeva E.Z., Ishmuratova M.M. Izmenchivost' morfologicheskikh priznakov nekotorykh vidov roda Tulipa L. na Yuzhnom Urale [Variability of morphological features of some species of the genus Tulipa L. in the Southern Urals]. Izvestiya Samarskogo nauchnogo tsentra Rossiyskoy akademii nauk [Izvestia of Samara Scientific Center of the Russian Academy of Sciences], 2014, vol. 16, № 5-5, pp. 1650-1653.

5. Lyu T.N., Badayev R.V., Obgenova D.A., Lidzhiyeva N.Ts. Izmenchivost' priznakov rasteniy Tulipa gesneriana $\mathrm{v}$ tsenopopulyatsii, polimorfnoy po okraske tsvetkov [Variability of Tulipa gesneriana plant traits in coenopopulation polymorphic by flower color]. Vestn. Kalmytskogo un-ta [Bulletin of the Kalmyk University], 2013, № 1 (17), pp. 39-43.

6. Ochirova A.S., Kondyshev O.V., Ovadykova Zh.V., Lidzhiyeva N.Ts. Fitotsenoticheskaya priurochennost' tsenopopulyatsii Tulipa biflora v Kalmykii [Phytocenotic confinement of coenopopulation Tulipa biflora in Kalmykia]. V mire nauchnykh otkrytiy [In the World of Scientific Discoveries]. Krasnoyarsk, 2015, № 2 (62), pp. 53-66.

7. Ochirova A.S., Golovkova A.M., Ovadykova Zh.V., Lidzhiyeva N.Ts. Semennaya produktivnost' rasteniy $\mathrm{v}$ tsenopopulyatsiyakh Tulipa biflora $\mathrm{v}$ usloviyakh Respubliki Kalmykiya [Seed productivity of plants in price groups Tulipa biflora in the Republic of Kalmykia]. V mire nauchnykh otkrytiy [In the World of Scientific Discoveries]. Krasnoyarsk, 2017, vol. 9, № 4 (2), pp. 137-149.

8. Krasnaya kniga Volgogradskoy oblasti. (Rasteniya i griby) [The Red Book of the Volgograd region. (Plants and mushrooms)]. Volgograd: Volgograd Publishing House, 2006, vol. 2, 236 p.

9. Krasnaya kniga Krasnodarskogo kraya. (Rasteniya i griby) [Red Book of Krasnodar Territory. (Plants and mushrooms)]. Krasnodar: OPO« Design Bureau № $1 », 2007,640 \mathrm{p}$.

10. Krasnaya kniga Rostovskoy oblasti: $v 2$ t. Rasteniya i griby [The Red Book of the Rostov region: in 2 tons. Plants and mushrooms]. Rostov-on-Don: Ministry of Natural Resources of the Rostov Region, 2014, vol. 2, 344 p. 
11. Krasnaya kniga Respubliki Kalmykiya: $v 2$ t. Redkie i nakhodyashchiesya pod ugrozoy ischeznoveniya rasteniya $i$ griby [The Red Book of the Republic of Kalmykia: in 2 vol. Rare and endangered plants and mushrooms]. Elista: ZAOr «SPE «Dzhangar», 2014. Vol. 2. 199 p.

12. Tsenopopulyatsii rasteniy (osnovnye ponyatiya i struktura) [Cenopopulation of plants (basic concepts and structure)]. M.: Science, 1976. 217 p.

13. Zaytsev G.N. Matematicheskiy analiz biologicheskikh dannykh [Mathematical analysis of biological data]. Moscow: Science, 1991, $180 \mathrm{p}$.

\section{ДАННЫЕ ОБ АВТОРАХ}

Анжаев Николай Олегович, магистрант

Федеральное государственное бюджетное общеобразовательное учреждение высшего образования «Калмыцкий государственный университет имени Б.Б. Городовикова»

ул. Пушкина, 11. г. Элиста, 358009, Российская Федерация anzhaev.nikola@yandex.ru

\section{Борлыков Савр Хонгорович, магистрант}

Федеральное государственное бюджетное общеобразовательное учреждение выстего образования «Калмыцкий государственный университет имени Б.Б. Городовикова»

ул. Пушкина, 11. г. Элиста, 358009, Российская Федераиция borlykovsh@yandex.ru

Овадыкова Жанна Васильевна, к. с.-х. н., доцент кафедры метрологии, стандартизации и сертификации Федеральное государственное бюджетное образовательное учреждение выстего образования «Ухтинский государственный технический университет»

ул. Первомайская, 13. г. Ухта, 169300, Российская Федерачия zhanna_ovadykova@mail.ru

Лиджиева Нина Цереновна, д.б.н., профессор, заведующий кафедрой общей биологии и физиологии Федеральное государственное бюджетное общеобразовательное учреждение высшего образования "Калмыцкий государственный университет имени Б.Б. Городовикова» ул. Пушкина, 11. г. Элиста, 358009, Российская Федерация for-lidjieva@yandex.ru 


\section{DATA ABOUT THE AUTHORS}

Anzhaev Nikolay Olegovizh, Graduate Student

Kalmyk State University named after B.B. Gorodovikova

11, Pushkin Str., Elista, 358009, Russian Federation

anzhaev.nikola@yandex.ru

ORCID: 0000-0002-4849-5327

Borlykov Savr Hongorovyzh, Graduate Student

Kalmyk State University named after B.B. Gorodovikova

11, Pushkin Str., Elista, 358009, Russian Federation

borlykovsh@yandex.ru

ORCID: 0000-0003-3339-2314

Ovadykova Zhanna Vasilevna, Candidate of Agriculture, Associate Professor of the Department of Metrology, Standardization and Certification Ukhta State Technical University

13, Pervomaiskaya Str.,Ukhta, 169300, Russian Federation

zhanna_ovadykova@mail.ru

SPIN-code: 8079-8320

ORCID: 0000-0001-7539-6909

Lidzhieva Nina Tserenovna, Doctor of Biology, Professor, Head of the Department of General Biology and Physiology

Kalmyk State University named after B.B. Gorodovikova

11, Pushkin Str., Elista, 358009, Russian Federation

for-lidjieva@yandex.ru

SPIN-code: 3661-2682

ORCID: 0000-0003-2668-698X 